\title{
Dermoscopic Appearances in the Superficial and Deep Type of Infantile Hemangioma
}

\author{
Muneharu Miyake, Naoki Oiso", Akira Kawada \\ Department of Dermatology, Kinki University Faculty of Medicine, Osaka, Japan. \\ Email: "naoiso@med.kindai.ac.jp
}

Received June $4^{\text {th }}, 2012$; revised July $8^{\text {th }}, 2012$; accepted July $25^{\text {th }}, 2012$

\begin{abstract}
Infantile hemangioma is clinically classified as superficial, superficial and deep (mixed), and deep. Dermoscopy can be used for analyzing vascular structure and for classifying infantile hemangioma. Here, we focus on vascular features of the superficial and deep type of infantile hemangioma and show the three characteristic dermoscopic forms, mostly reddish, diffuse reddish, and cerebriform reddish.
\end{abstract}

Keywords: Dermoscopy; Infantile Hemangioma; Classification

\section{Introduction}

Precise diagnosis and evaluation are essential to design treatment strategies for infantile hemangioma and capillary malformations. Dermoscopy is useful for immediate and precise diagnosis for infantile hemangioma without proliferation (infantile hemangioma precursor) from capillary malformation of port-wine stain [1-3]. Infantile hemangioma is clinically classified as superficial, superficial and deep (mixed), and deep. Dermoscopy can distinguish vascular structure between the superficial and mixed types [4]. Here, we depict the three vascular-dominate features in the mixed type of infantile hemangioma, mostly reddish, diffuse reddish and cerebriform reddish.

\section{Case Series}

Case 1 was an 11-month-old boy with a dark reddish slightly elevated plaque $20 \times 16 \mathrm{~mm}$ in size on the right

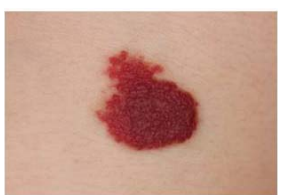

(a)

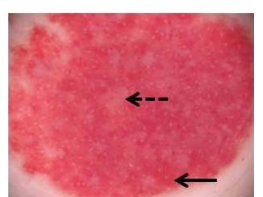

(b)

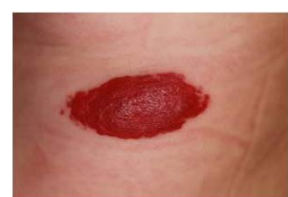

(c)

chest (Figure 1(a)). An erythematous macule was present at birth as a dark reddish macule and gradually grew into a plaque lesion. Dermoscopy showed reddish lesions (arrow) and focal pinkish annular lesions (dotted arrow) (Figure 1(b)).

Case 2 was a 2 -month-old girl with a dark reddish elevated plaque $35 \times 15 \mathrm{~mm}$ in size on the left upper back (Figure 1(c)). An erythematous macule appeared one week after birth and gradually grew into the plaque lesion. Dermoscopy showed a diffuse reddish form composed of diluted red vessels surrounded by a pinkish structure (Figure 1(d)).

Case 3 was a 6-month-old girl with a dark reddish, obviously elevated plaque with a cerebriform elevation $30 \times$ $15 \mathrm{~mm}$ in size on the left abdomen (Figure 1(e)). The eruption was present at birth and gradually developed into the elevated plaque lesion. Dermoscopy revealed cerebriform components (arrow), including dilated red

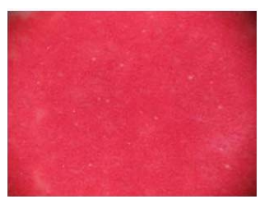

(d)

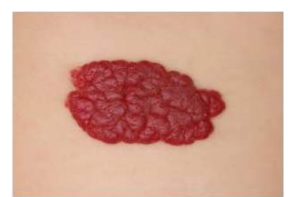

(e)

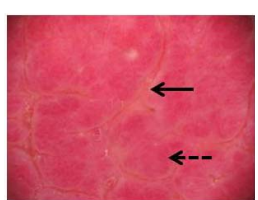

(f)

Figure 1. (a) An 11-month-old boy having a plaque of a superficial and deep infantile hemangioma; (b) Dermoscopic appearance of Figure 1(a). Dermoscopy showed reddish lesions (arrow) and focal pinkish annular lesions (dotted arrow); (c) A 2-month-old girl having an elevated plaque of a superficial and deep infantile hemangioma; (d) Dermoscopic picture of Figure 1(c). Dermoscopy showed a diffuse reddish form composed of diluted red vessels surrounded by a pinkish structure; (e) A 6-month-old girl having an obviously elevated plaque with a cerebriform elevation of a superficial and deep infantile hemangioma; (f) Dermoscopic photograph of Figure 1(e). Dermoscopy revealed the cerebriform components (arrow), including dilated red vessels surrounded by a pinkish structure (dotted arrow).

\footnotetext{
${ }^{*}$ Corresponding author.
} 
vessels surrounded by pinkish structure (dotted arrow) (Figure 1(f)).

\section{Discussion}

We previously summarized the dermoscopic features of polymorphous vascular structures in infantile hemangioma, a superficial type with a polymorphous vascular structure with no obvious red linear vessels or red dilated vessels, and a mixed type with polymorphous vascular structure with red linear and red dilated vessels [4]. Here, we focus on the dermoscopic appearances of vasculardominant features of the mixed type infantile hemangioma. Dermoscopy can subdivide a mixed type into polymorphous vascular forms [3], mostly reddish, diffuse reddish, and cerebriform reddish.

As shown previously as well as here, dermoscopy can be used to classify infantile hemangioma as either superficial or mixed, and to subdivide the mixed type as either mild to severe.

\section{REFERENCES}

[1] N. Oiso, M. Kimura, S. Kawara and A. Kawada, "Clinical, Dermoscopic and Histopathologic Features in a Case of Infantile Hemangioma without Proliferation," Pediatric Dermatology, Vol. 28, No. 1, 2011, pp. 66-68. doi:10.1111/j.1525-1470.2010.01363.x

[2] F. Toledo-Alberola, F. I. Betlloch-Mas, L. Cuesta-Montero, I. Ballester-Nortes, J. Bañuls-Roca, E. Calonje and M. T. Martínez, "Abortive Hemangiomas. Description of Clinical and Pathological Findings with Special Emphasis on Dermoscopy," European Journal of Dermatology, Vol. 20, No. 4, 2010, pp. 497-500.

[3] F. Vázquez-López, P. Coto-Segura, A. Fueyo-Casado and N. Pérez-Oliva, "Dermoscopy of Port-Wine Stains," Archive of Dermatology, Vol. 143, No. 7, 2007, p. 962. doi:10.1001/archderm.143.7.962

[4] N. Oiso and A. Kawada, "The Dermoscopic Features in Infantile Hemangioma," Pediatric Dermatology, Vol. 28, No. 1, 2011, pp. 591-593. doi:10.1111/j.1525-1470.2011.01385.x 